
$\$$ Research Square
Preprints are preliminary reports that have not undergone peer review.
They should not be considered conclusive, used to inform clinical practice,
or referenced by the media as validated information.

\title{
Microsponges for controlled release and enhanced oral bioavailability of carbamazepine
}

Karam F. Abdalla ( $\sim$ karamfawzyabdalla@gmail.com )

Tanta University Faculty of Pharmacy https://orcid.org/0000-0002-2793-2997

Mohamed A. Osman

Tanta University Faculty of Pharmacy

Ahmed T. Nouh

Delta University for Science and Technology

Gamal M. El Maghraby

Tanta University Faculty of Pharmacy

\section{Research Article}

Keywords: Carbamazepine, carbamazepine dihydrate, bioavailability, microsponges

Posted Date: March 10th, 2021

DOl: https://doi.org/10.21203/rs.3.rs-266626/v1

License: (c) (1) This work is licensed under a Creative Commons Attribution 4.0 International License. Read Full License

Version of Record: A version of this preprint was published at Journal of Drug Delivery Science and Technology on October 1st, 2021. See the published version at https://doi.org/10.1016/j.jddst.2021.102683. 


\section{Abstract}

The oral absorption and hence the oral bioavailability of carbamazepine (CBZ) is variable even after administration of rapidly dissolving formulation. This problem was attributed to supersaturation of CBZ and transformation to the less soluble carbamazepine dihydrate (CBD). Accordingly, formulation of sustained release products of $\mathrm{CBZ}$ is a promising approach to overcome this problem. Microsponges is an emerging formulation which can help in this direction. The aim of this work was to optimize the composition of microsponges for better encapsulation and sustained release of CBZ for oral administration. CBZ microsponges were prepared using quasi emulsion solvent diffusion technique with varying composition of ethyl cellulose and polyvinyl alcohol (PVA). Microsponges were evaluated using Fourier transform infrared spectroscopy (FTIR), differential scanning calorimetry (DSC) and X-ray diffraction. Production yield, entrapment efficiency and surface morphology of microsponges were assessed in addition to drug release. Optimum formulation was administered orally to albino rabbits to evaluate the oral bioavailability with reference to unprocessed CBZ. The Instrumental analysis reflected the encapsulation of CBZ in amorphous or molecularly dispersed form in the microsponges. The size and entrapment efficiency of the microsponges increased with increasing polymer contents. This was associated with reduction in CBZ release. Optimum formulation enhanced the oral absorption of CBZ. This was manifested by 2.6 -fold increase in the area under the plasma concentration versus time curve compared to that of unprocessed CBZ. The study introduced microsponges as promising carriers for sustained oral delivery of CBZ.

\section{Introduction}

Carbamazepine (CBZ) is an anti-epileptic agent which is used in the therapy of trigeminal neuralgia, epilepsy and bipolar disorders. Unmodified CBZ tablets show irregular absorption after oral administration. This results in a very variable. $T_{\max }$ with CBZ maximum plasma level being reached after 4 to 32 hours. This irregular and slow absorption was shown to relate to the slow dissolution rate of CBZ. Enhancement of the dissolution rate is said to improve the rate and extent of absorption [1, 2]. In addition to poor dissolution, CBZ can undergo polymorphic transitions with at least four polymorphs being identified (I, II, III, and IV). In addition, CBZ can exist in a dihydrate form which has significantly lower solubility and dissolution rate compared to the corresponding anhydrous form. The conversion of CBZ to carbamazepine dihydrate (CBD) in the gastrointestinal tract can add rate-limiting factor in CBZ bioavailability after oral administration. Rapid dissolution of CBZ from immediate release formulations may result in supersaturation with subsequent recrystallization into CBD. This can negatively affect the rate and extent of $\mathrm{CBZ}$ absorption. Formulation of $\mathrm{CBZ}$ as controlled release dosage form can decrease the chance for supersaturation eliminating the problem of CBD formation [1]. Moreover, prolonged and continuous administration of CBZ can result in auto-induction of its metabolizing enzymes. The elimination half life $\left(t_{1 / 2}\right)$ will be shortened with time. For example, the $t_{1 / 2}$ of CBZ was around 24 hours after administration of single dose. This $t_{1 / 2}$ can be reduced to about 12 hours after repeated administration in absence of other enzyme inducers. Co administration of CBZ with other enzyme 
inducers can further decrease the $t_{1 / 2}$ [3]. This specification added more to the benefit of sustained release formulation which will be more suitable for chronic therapy [4].

Alternative strategies have been employed to formulate extended release formulations. These include preparation of matrix tablets which depends on polymeric matrix that liberate the drug slowly but the release rate from this form is variable depending on food, GIT transit time and the change in the effective surface area [5]. Osmotic pump is another strategy for single unit controlled release systems. This system relies on osmotic pressure as the driving force for controlled drug release but technical difficulties in the film is the main problem which may lead to dose dumping [6]. The use of ion exchange resin as a tool for controlled release drug delivery provides another approach. However, its success depends on the regional ions in the GIT and may be affected by food [7]. Development of multiunit particulate drug delivery systems is preferred over single unit controlled release strategies. These include microencapsulation and liposomes. Microcapsules may not be able to provide strict control on drug the release rate as it may depend on the time required for rupture of the wall. Liposomes suffer from poor drug entrapment in addition to physical, chemical and microbial instability [8]. Microsponges are emerging strategy for development of controlled release particulate drug delivery system. They are spongy like microparticles which are characterized by their highly porous surface. The dominant morphology of microsponges is the spherical shape. They can be devised in a wide particle size range, the smallest can be around $5 \mu \mathrm{g}$ and size values up to hundreds of microns. The porous surface of these particles allows for the existence of very small pores with the recorded average pore size value of $0.25 \mu \mathrm{m}$. The small pore size makes the particle self sterile due to inability of microorganism to penetrate into the pores. Microsponges can be fabricated using different polymer composition and can resist high temperature and wide $\mathrm{pH}$ range. Microsponges can entrap high concentrations of drug and can be dried into free flowing products [9]. Microsponges have been reported to control the rate of drug release by entrapment in the microporous structure [10]. The release profile and release rate of drugs can be tailored by modifying the composition of microsponge [11].

Accordingly, the objective of the current study was to optimize the composition of carbamazepine microsponges to produce microsponges with optimum specifications. The effect of drug (CBZ) polymer (EC) ratio and polyvinyl alcohol (PVA) concentration on the characteristics of microsponges was investigated. The study was extended to evaluate the optimum formulation in vivo.

\section{Materials And Methods}

\section{Materials}

Carbamazepine was obtained as gift sample from Medizen Pharmaceutical industries, Alexandria. Dichloromethane was purchased from Al-Nasr Chemical Company, Cairo Egypt. Ethyl cellulose N50 was supplied as a gift sample from Sigma pharmaceutical industries, Quesna, Egypt. Methanol HPLC grade Lobachemie, India. Polyvinyl Alcohol (PVA) was purchased from Nice Chemicals, Kerala, India. All other chemicals used in the present study were of analytical grade. 


\section{Spectrophotmetric determinations}

The concentrations of carbamazepine were in the in vitro samples were determined by UV spectrophotometry using double beam spectrophotometer made by Thermo Fisher Scientific (Madison, USA). Determinations were performed at $284 \mathrm{~nm}$ and the calibration curve was linear in the concentration range of $2-20 \mu \mathrm{g} / \mathrm{ml}$ and the equation of the calibration curve was $Y=0.0536 X+0.0458)$. The slope of this standard curve $0.0536 \pm 0.0005$ and the intercept was $0.0458 \pm 0.0025$.

\section{High performance liquid chromatography (HPLC)}

The in-vivo study involved determination of carbamazepine concentrations in the plasma. This was achieved using HPLC system (Agilent isocratic controller, Agilent, Germany) which was supported PDA detector and an automatic sampling system with Quat pump. The mobile phase consisted a mixture of methanol and filtered distilled water (50:50, v/v) flowing at a flow rate of $1 \mathrm{ml} /$ minute. The stationary phase was a reversed phase $10 \mu \mathrm{m}$ particles $\mathrm{C} 18$ column, $150 \mathrm{~mm}$ in length with and internal diameter of $4.6 \mathrm{~mm}$ (Inertsil ODS C18, Waters). Chromatographic separation was conducted at ambient temperature and drug concentration was determined at $285 \mathrm{~nm}$. The whole process including data analysis was controlled by OpenLAB software (Agilent 1260 infinity, Germany) [12].

The calibration curve was prepared using stock solutions containing $1000 \mu \mathrm{g} / \mathrm{ml}$ of CBZ or the internal standard (propyl paraben) which were prepared in methanol. This was used to prepare the working solutions which were prepared by serial dilutions of CBZ in methanol to produced solutions containing 5 , $10,20,50,100,200$ and $400 \mu \mathrm{g} / \mathrm{ml}$ of CBZ with fixed concentration of the internal standard $(100 \mu \mathrm{g} / \mathrm{ml})$. These working solutions were used to construct the calibration curve in the plasma by adding $100 \mu \mathrm{l}$ of

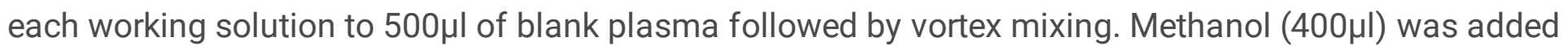
to each mixture with mixing to precipitate the proteins. The precipitated protein was separated by centrifugation and $50 \mu \mathrm{l}$ of the supernatant was injected into the HPLC. These procedures produced samples with drug concentration of $0.5,1,2,5,10,20$ and $40 \mu \mathrm{g} / \mathrm{ml}$ with fixed concentration of internal standard $(10 \mu \mathrm{g} / \mathrm{ml})$. The calibration curve was constructed by plotting the peak area ration of CBZ to the internal standard as a function of CBZ concentration [12]. The actual plasma samples were treated by adding $100 \mu \mathrm{l}$ of internal standard $(100 \mu \mathrm{g} / \mathrm{ml})$ to $500 \mu \mathrm{l}$ of plasma followed by vortex mixing. Methanol $(400 \mu l)$ was added to each mixture with mixing to precipitate the proteins as before.

\section{Preparation of carbamazepine microsponges}

Carbamazepine containing microsponges were prepared using the quasi-emulsion solvent diffusion technique. This method is reported to be simple with reproducible results [10]. The composition of microsponges is presented in Table 1. Dichloromethane which solubilize ethyl cellulose and carbamazepine was used as the internal solvent with PVA aqueous solution being employed as external phase. Ethyl cellulose and carbamazepine were dissolved in dichloromethane. This solution was added dropwise to the aqueous solution of PVA using $18 \mathrm{G}$ syringe. This process was conducted under continuous stirring at $500 \mathrm{rpm}$ using an overhead stirrer. Stirring continued for 4 hours at the end of which 
the microsponges were harvested by filtration and were left to dry at ambient temperature. The dry microsponges were weighed to calculate the production yield which was calculated using equation 1 .

$\%$ Practical yield $=\frac{\text { Amount of microsponges obtained X } 100}{\text { Total weight of drug and excipients }}$

.. (Equation 1)

\section{Scanning electron microscopy (SEM)}

The morphological characteristics of microsponges were assessed by scanning electron microscopy. The microsponges were coated with gold at room temperature. The morphology of the microsponges was studied using SEM (JEOL JSM-5300, Japan) which is supported with sputter coater device (JFC-1100E ion).

\section{Determination of drug content and encapsulation efficiency}

Crushed microsponges $(100 \mathrm{mg}$ ) were dissolved in $10 \mathrm{ml}$ of methanol and the solution was filtered. The filtrate $(1 \mathrm{ml})$ was suitable diluted and the concentration of the drug was quantified spectrophotometrically at $284 \mathrm{~nm}$. These procedures were repeated three times and the drug content was determined using equation and the encapsulation efficiency was calculated using equation 3 .

$$
\begin{aligned}
& \text { Drug content }(\% w / w)=\frac{\text { Amount of drug recovered in } 100 \mathrm{mg}}{100} X 100 \ldots \ldots \text { (Equation2) } \\
& \text { Encapsulation efficiency }(\%)=\frac{\text { Estimated drug content }}{\text { Theoritical drug content }} X 100
\end{aligned}
$$

\section{Differential scanning calorimetry (DSC)}

DSC was utilized to investigate the effect of encapsulation of carbamazepine into microsponges on the thermal pattern of the drug. This was achieved using differential scanning calorimeter (DSC6 module, Perkin Elmer, Waltham, USA). Carbamazepine (2-4 mg) or equivalent microsponges was encapsulated into aluminum pans. These pans were loaded in the furnace of the equipment with an empty pan serving as a reference. The sample was heated from 30 to $400^{\circ} \mathrm{C}$ at a heating rate of $10^{\circ} \mathrm{C} /$ minute. The test was conducted under continuous flow of nitrogen gas. Data acquisition and manipulations were achieved using Pyris ${ }^{\circledR}$ software.

\section{Fourier Transform Infrared spectroscopy (FTIR)}

FTIR was performed to monitor possible interactions between carbamazepine and the polymers. The study utilized FTIR spectrophotometer (Bruker Tensor 27, Ettlingen, Germany) which is supported by a DLaTGS detector. Carbamazepine, ethyl cellulose or the corresponding microsponges were mixed with 
potassium bromide. The mixture was prepared as thin disks by direct compression before loading into the sampling holder of the spectrophotometer. The FTIR spectra were collected in the range of 4000$400 \mathrm{~cm}^{-1}$.

\section{X-ray diffraction (XRD)}

The crystallinity of carbamazepine was monitored before and after encapsulation into the microsponges. This was achieved using an X-ray powder diffractometer (Bruker MeasSrv- D2-208219/D2-208219) which employed secondary graphite monochromated at $30 \mathrm{kV} / 10 \mathrm{~mA}$. The data were collected at a scanning steps of $0.03^{\circ}$ to cover the two-theta range of $3-60^{\circ}$ at a temperature of $25^{\circ} \mathrm{C}$.

\section{Determination of drug release}

The release rate of carbamazepine from the prepared microsponges was assessed using USP type II dissolution (paddle method) equipment in which the paddle was rotated at $100 \mathrm{rpm}$. The release study employed continuous $\mathrm{pH}$ variation method in which the formulation was subjected for $\mathrm{pH} 1.2$ for 2 hours at the end of which the $\mathrm{pH}$ was adjusted to 7.4 for 6 hours [13]. Briefly, microsponge equivalent to $200 \mathrm{mg}$ of carbamazepine was add to dissolution vessels containing $500 \mathrm{ml}$ of $0.1 \mathrm{~N} \mathrm{HCl}$ containing $1 \%$ sodium lauryl sulphate which were previously equilibrated to $37^{\circ} \mathrm{C}$. Samples $(5 \mathrm{ml})$ were collected at predetermined time intervals for 2 hours. The dissolution medium was replenished after each sample. The $\mathrm{pH}$ was then adjusted to 7.4 by addition of $55 \mathrm{ml}$ of $4 \mathrm{~N}$ sodium hydroxide and the volume was adjusted to 900 using $20 \mathrm{mM}$ sodium dihydrogen phosphate containing $1 \%$ sodium lauryl sulphate. Samples were collected and the dissolution medium was replenished as before. The collected samples were filtered and suitably diluted if required before was determination of the drug content spectrophotometrically at $284 \mathrm{~nm}$. The cumulative amount of carbamazepine released was expressed as percentage of the dose and was plotted as a function of time to develop the release profile. The release profile was used to compute the release efficiency which was calculated from the area under the release profile relative to the theoretical area of $100 \%$ release at all time points [14].

The release kinetics was computed by fitting the release data for zero, first, Higuchi and Korsmyer and Peppas kinetic models.

\section{In vivo study}

The study compared the oral bioavailability of carbamazepine from the microsponges relative to a suspension of the unprocessed carbamazepine. The study utilized 6 male albino rabbits (average weight of $2.18 \pm 0.1 \mathrm{Kg}$ ). The animal study was approved by Faculty of Pharmacy, Tanta University Ethical Committee (approval number (2042016). The study was conducted in a parallel experimental design in which the rabbits were divided into two groups (3 rabbits each). The first group administered carbamazepine-loaded microsponges (group A) and the second group administered carbamazepine aqueous suspension (group B) which served as control. The rabbits were given free access to water with food restriction for overnight before administration. Each rabbit received a dose equivalent to $200 \mathrm{mg}$ 
carbamazepine suspended in $10 \mathrm{ml}$ water by oral by oral feeding tube. The rabbits were kept in cages and had free access to food and water after $6 \mathrm{~h}$. Serial blood samples $(1.0 \mathrm{ml})$ were withdrawn from the marginal ear vein into a vial containing sodium citrate (3.2\%) $(50 \mu \mathrm{l})$ at predose and post-doses $(1,2,3,4$, $6,8,10,12$ and $24 \mathrm{~h}$ ). The blood samples were mixed and centrifuged at $5000 \mathrm{rpm}$ for $10 \mathrm{~min}$ within 1 hour of collection. This separated the plasma which was stored at $-20{ }^{\circ} \mathrm{C}$ until time of analysis. Assay of drug in plasma was conducted using HPLC as described above [15].

\section{Statistical analysis}

Statistical analysis employed Kruskal Wallis test with tukey`s multiple comparison being used to probe the significance between groups.

\section{Results And Discussion}

The objective of this study was to optimize the composition of microsponges. Ethyl cellulose was used as the principle polymer and PVA was employed as surfactant. The concentration of ethyl cellulose was varied with the drug being included at fixed amount. This provided different levels for drug to polymer ratio. Three concentrations of PVA were employed for each drug to polymer ratio. This provided nine formulations. The stirring rate was kept constant (500 rpm).

\section{Production Yield (PY)}

Table 1 presents the characteristics of the prepared formulations. The percentage production yield depended on the composition of the formulations and depended on the concentration of the emulsifier used. At fixed concentration of PVA the production yield increased by increasing the proportions of ethyl cellulose. With respect to the effect of PVA, the production yield (PY) decreases upon increasing the concentration of PVA at fixed ethyl cellulose concentration (fixed drug to polymer ratio, Table 2). The increase in production yield in presence of high concentration of ethyl cellulose can be attributed to increased viscosity which reduces the rate of diffusion of the organic phase to the aqueous phase. This can delay polymer precipitation providing greater chance for droplet formation. Inversely, lower concentration of ethyl cellulose provides less viscous organic phase which undergoes rapid diffusion into the outer phase with subsequent rapid mixing and faster elimination of the solvent. This can reduce the coalescence time resulting solidification of the polymer and drug before droplet formation leading to low yield. With respect to the effect of PVA, increasing the concentration can result in self association of some of the PVA away from the oil-water interface creating an alternative hydrophobic domain which can solubilize part of the polymer and drug reducing the amount of the developed particles. This results in reduction of the production yield. Similar results were recorded by other investigators and were similarly discussed [16].

\section{Morphology and size of microsponge}


The morphology and particle size of the prepared microsponges were determined by SEM analysis. Figure 1 shows scanning electron micrographs of plain microsponge and Fig. 2 shows the scanning electron micrographs medicated formulations. The recorded particle size values are presented in Table 2 . The plain particles were spherical with smooth surface (Fig. 1). This morphology is similar to that recorded by other investigators [10]. Incorporation of carbamazepine into the particles produced spherical particles with rough and porous surface. The roughness of the surface decreases by increasing the relative proportion of ethyl cellulose to carbamazepine (Fig. 1, 2). Similar morphology was published by other investigators [10].

The particle size of the microsponges depended on the composition of the formulation. Plain microsponges $F_{0}$ with respect to the medicated microsponges, increasing the concentration of ethyl cellulose resulted in significant increase in the particle size $(P<0.05)$. This increase in the particle size can be explained on the base of increased viscosity of the organic layer at higher concentration of ethyl cellulose. This can decrease the diffusivity of the polymer and drug to the aqueous phase producing enough time for development of large droplet and hence formation of larger particles. With respect to the effect of PVA, it showed significant effect on the particle size only in formulations containing the lowest concentration of ethyl cellulose with the particle size reducing upon increasing the concentration of PVA (Table 2). This reduction of particle size can be attributed to reduction of the interfacial tension with subsequent formation of smaller droplet size and subsequently smaller particles. This effect is overshadowed by the viscosity in formulations containing higher concentration of ethyl cellulose in which the effect of viscosity dominated. Thus, at constant ethyl cellulose concentration, the particle size values of F4, F5 and F6 which contained increasing concentration of PVA were similar ( $P>0.05)$. The same trend was shown when comparing formulations F7, F8 and F9 (Table 2). Mahmoud and coworkers [16] reported no significant effect for the concentration of PVA on the particle size of microsponge [16]. The discrepancy of the published finding and the recorded data at low concentration of ethyl cellulose can be attributed to the use of different concentration or different viscosity grade of ethyl cellulose.

\section{Entrapment efficiency and drug content}

The calculated entrapment efficiency and drug content values are presented in Table 2. The entrapment efficiency depended on the composition of the tested formulation. Increasing the concentration of ethyl cellulose resulted in significant increase $(P<0.05)$. This increase in expected and can be explained on the base of increased relative proportion of the polymer to the drug. Taking into consideration the fact that the main matrix of the microsponge is composed from the polymer, the increase in entrapment efficiency with increased polymer concentration can be explained. Considering the effect of emulsifier, formulations containing similar polymer to drug ratio with increasing emulsifier concentration were compared. This comparison reflected a trend of increased entrapment with increasing the concentration of PVA. This increase became significant when moving from 0.1 to $1 \% \mathrm{w} / \mathrm{v}$ of PVA $(P<0.05)$. This increase can be attributed to the micellar solubilization which became more efficient at higher concentration of PVA. With respect to the drug content which was calculated as the amount of drug recovered relative to the total weight of the formula, the recorded values reflect a trend of increased drug content with increased 
emulsifier concentration at fixed polymer to drug ratio (Table 2). Increasing the polymer concentration at fixed PVA concentration provided similar drug content despite of increased entrapment efficiency. This similarity is attributed to the increase in the polymer content which masked the apparent increase in the entrapment efficiency. Similar pattern was reported for the effect of polymer composition and emulsifier on the entrapment efficiency and drug content [16].

\section{DSC study}

Figure 3 shows representative thermograms of carbamazepine in pure state and after encapsulation in different formulations of the microsponges. The thermogram of pure carbamazepine showed small and intense sharp endothermic peaks which were recorded at $174{ }^{\circ} \mathrm{C}$ and at $192^{\circ} \mathrm{C}$, respectively. These peaks are the characteristic for carbamazepine and are assigned for its melting [17]. The thermogram also showed broad endothermic peak at $272{ }^{\circ} \mathrm{C}$, corresponding to the decomposition of carbamazepine. Similar thermal behavior was recorded by other investigators who showed polymorphic transitions of carbamazepine $[18,19]$. The thermal behavior of unprocessed ethyl cellulose showed a baseline curvature at $67^{\circ} \mathrm{C}$ followed by weak endothermic followed by exothermic transitions at 184 and $192{ }^{\circ} \mathrm{C}$, respectively. This thermal behavior is similar to that recorded by other investigators who attributed this thermal behavior to the amorphous nature of ethyl cellulose. The polymer underwent glass transition due to molecular mobility which started by the baseline flick at $67^{\circ} \mathrm{C}$ and completed by the endothermic/exothermic events [20]. The thermal behavior of plain microsponge did not show significant alterations compared to that of ethyl cellulose (Fig. 3). This finding is expected taking into consideration the fact that ethyl cellulose is the main component of the microsponge and PVA perform its function at the interface with minor amounts being adsorbed on the surface of particles.

With respect to the medicated microsponges, broad endothermic peak was in the temperature range of 45 to $85^{\circ} \mathrm{C}$. This endotherm overlapped with the glass transition of the polymer and is attributed to evaporation of adsorbed moisture. The medicated formulations revealed very weak endotherm at $188^{\circ} \mathrm{C}$, corresponding to the melting of carbamazepine. This weak endotherm does not correlate with the amount of drug in the formulation. This suggest partial transformation of carbamazepine into amorphous state or its solubility in the polymer matrix. The later supposition is strengthened by the data in the thermograms which reflected reduction in the peak corresponding to the melting transition of the drug in formulations containing higher proportions of ethyl cellulose. The decomposition endotherm of carbamazepine was shown as weak broad peak at $265^{\circ} \mathrm{C}$. The concentration of PVA did not show any significant effect on the phase behavior of the formulations (Fig. 3). Similar thermal behavior has been reported after encapsulation of drugs in ethyl cellulose or Eudragit microsponges of different composition [21-23].

\section{FTIR studies}

Figure 4 shows the FTIR spectra of carbamazepine, ethyl cellulose and their microsponges formulations (F1-F9). The FTIR spectrum of pure untreated carbamazepine reflects the peaks corresponding to its 
structural features. The $\mathrm{N}-\mathrm{H}$ symmetric and asymmetric stretching vibrations were seen at $3362 \mathrm{~cm}^{-1}$ and $3343 \mathrm{~cm}^{-1}$, respectively. This complies with the expected wave number of this group which is suggested to show near 3350 to $3180 \mathrm{~cm}^{-1}$ [24]. The absorption band at $1384 \mathrm{~cm}-1$ is due to $\mathrm{NH} 2$ rocking. The existence of $\mathrm{NH}$ valence vibration at $3462 \mathrm{~cm}^{-1}$ is considered as an evidence that $\mathrm{CBZ}$ could be neither polymorph II $\left(3474 \mathrm{~cm}^{-1}\right)$ nor polymorph I $\left(3484 \mathrm{~cm}^{-1}\right)[18,25]$. This suggests that the tested CBZ is in form of polymorph III. The $\mathrm{C}=0$ stretching vibration was shown as strong absorption band at $1674 \mathrm{~cm}^{-1}$. The $\mathrm{C}-\mathrm{H}$ stretching vibrations were seen as two absorption bands at $3110 \mathrm{~cm}^{-1}$ and $3200 \mathrm{~cm}^{-1}$. C-N stretching vibrations were seen at 1307 and $1246 \mathrm{~cm}^{-1}$. The absorption band at $1595 \mathrm{~cm}^{-1}$ can be attributed to $\mathrm{C}=\mathrm{C}$ (Fig. 4). This spectrum is similar to that published by other researchers [26].

The FTIR spectrum of ethyl cellulose was characterized by its $\mathrm{OH}$ stretching vibrations which appeared at $3476 \mathrm{~cm}^{-1}$ The other important peaks have been shown at 1098 , and $1414 \mathrm{~cm}^{-1}$ and can be attributed to $\mathrm{C}-\mathrm{O}-\mathrm{C}$ stretching and $\mathrm{C}-\mathrm{H}$ bending respectively (Fig. 4). Similar spectrum has been published for ethyl cellulose [27].

The FTIR spectra of the tested microsponges show broadening and shifting to lower wave number of the absorption bands corresponding to the $\mathrm{NH} 2$ group of $\mathrm{CBZ}$. This change reflects the existence of hydrogen bonding between ethyl cellulose and CBZ. The recorded evidence for hydrogen bonding correlates with the structural features of both materials and confirms the recorded DSC findings which suggest at least partial solubility of CBZ in the polymer matrix (Fig. 4). Similar findings have been published by other investigators who prepared nifedipine ethyl cellulose microparticles [28].

\section{$\mathrm{X}$ ray diffraction}

Figure 5 shows the $X$ ray diffraction pattern of unprocessed carbamazepine, ethyl cellulose and the selected microsponge formulation. The diffraction pattern of pure carbamazepine reflected its crystalline nature as reflected from the recorded diffraction peaks which were seen at $2 \theta$ values of $12.7,13.8,14.9$, $15.5,16.7,18.2,19.1,20.1,23.1,23.6,24.5,26.95$ and $31.6^{\circ}$. This diffraction behavior together with the FTIR spectrum and thermal analysis results can indicate the existence of carbamazepine in polymorphic form III. Similar diffractogram was recorded for carbamazepine by other investigators [29]. The diffraction pattern of ethyl cellulose confirms its amorphous nature as reflected from the absence of any diffraction peaks and the existence of broad heap at about $20.2^{\circ}$. The recorded diffractogram is similar to that recorded for ethyl cellulose [30]. The selected microsponge showed the existence of trace amounts of the drug in crystalline state with most of the entrapped carbamazepine being in amorphous or molecularly dispersed status. This is indicated by the existence of very weak diffraction peaks of carbamazepine (Fig. 5). Amorphization of drugs after encapsulation in microsponges was seen in other studies [31, 32].

\section{In vitro release of $\mathrm{CBZ}$ from microsponges}


Figure 6 shows the release profiles of CBZ from its unprocessed powder and different microsponges. The unprocessed CBZ liberated the drug completely during the course of the study. The unprocessed CBZ liberated $76.4 \%$ of the dose within 2 hours in the stomach phase and liberated the rest of the dose half an hour after shifting to the intestinal phase to reach more than $90 \%$ release. The release efficiency (RE) in the stomach phase was $58.11 \%$ with an overall release efficiency of $87.39 \%$ (Fig. 6 and Table 2). This release pattern is similar to that recorded for unprocessed CBZ [33]. Encapsulation of CBZ in microsponges reduced the rate of $\mathrm{CBZ}$ release with the release rate depending on the composition of the prepared microsponge. The similarity factor (f2) test was used to compare between the release profiles CBZ from different formulations. Based on this test CBZ release was significantly slower from microsponges compared with the unprocessed powder (F2 in the 17-33\%). This finding was evident irrespective to the composition of the tested microsponges. The reduction in the release rate was reflected also from the calculated release efficiency values both in the stomach phase and the overall release efficiency. These values were significantly decreased after encapsulation in microsponges compared with the unprocessed drug.

To investigate the effect of PVA concentration, formulation F1, F2 and F3 were compared. Similarly, the formulation groups F4-F6 and F7-F9 were compared. This comparison reflected no significant effect for the concentration of PVA on the release rate (F2 in the range 66-82\%). The factor that showed significant effect was the relative proportion of ethyl cellulose to CBZ. For example, comparing formulation 1 with formulation 4 there were significant reduction in the rate of $C B Z$ release $(F 2=42 \%)$. Likewise, there was significant reduction in CBZ release when comparing formulation 1 with formulation 7 ( $F 2=30 \%$ ). The same trend was recorded when comparing formulation 2 with formulations 5 and 8 or comparing $\mathrm{F} 3$ with F6 and F9 (Fig. 6). The same rank can be obtained by comparing the release efficiency of CBZ from different formulations (Table 2). These results indicate that increasing the concentration of ethyl cellulose in the formulation will provide greater control over the rate of CBZ release. This finding can be explained on the base of the hydrophobic nature of ethyl cellulose with increasing its concentration in the particles providing greater chance for matrix formation which may control the diffusion rate of CBZ within the particle [34], in addition to decreased porosity of the microsponges [35]. To verify this, the kinetics of CBZ release were researched. The release data of most of formulations were fitted better to Higuchi kinetic model suggesting that drug diffusion through the formed matrix is the limiting factor for drug release (Table 3). This finding supports the explanation of reduced rate of release after increasing the concentration of ethyl cellulose which is matrix former with higher concentration of the polymer increasing the degree of crosslinking and reducing the porosity of the matrix. Similar release pattern was recorded from ethyl cellulose-based particles [36, 37].

\section{In Vivo Evaluation}

The pharmacokinetic parameters of carbamazepine were monitored after oral administration of the drug in the form of aqueous dispersion or microsponge to rabbits. The recorded average plasma concentrations of carbamazepine are shown in Fig. 7 as a function of time. The calculated pharmacokinetic parameters are presented in Table 4. Fig. 7 reflects clear difference between the plasma 
profiles of carbamazepine after administration of simple aqueous dispersion of unprocessed carbamazepine powder or microsponge. Oral administration of the unprocessed carbamazepine produced a biphasic plasma concentration versus time plots with the profile showing two maxima. This can be attributed to possible enterohepatic recycling of carbamazepine. Similar profile was reported by other investigators $[38,39]$. This biphasic pattern can be responsible for the recorded high values of the elimination parameters (Table 4). Administration of carbamazepine in the form of microsponges resulted in significant increase in the area under the curve with the AUC being 2.6-fold compared with that of the unprocessed drug. This enhancement can be explained on the base that liberation of carbamazepine at slow rate from the microsponges eliminated the possibility of recrystallization of the drug in the stomach forming the slowly dissolving carbamazepine dihydrate (CBD) which is the major limitation of administration of immediate release formulation of CBZ [1]. Sustained release formulations of carbamazepine have been shown to enhance the oral bioavailability compared with the corresponding immediate release dosage forms [2]. Microsponges improved bioavailability of some drugs such as ketoprofen [40].

\section{Conclusion}

Carbamazepine was successfully encapsulated in microsponges. The specifications of microsponges depend on their composition. Increasing the viscosity of internal phase increased the drug entrapment efficiency into these microsponges with subsequent inhibition of drug loss during droplet formation. Increasing the concentration of ethyl cellulose increased the particle size and entrapment efficiency. The release rate was subsequently reduced by increasing ethyl cellulose concentration. Sustaining carbamazepine release was associated with increased oral bioavailability.

\section{Declarations}

\section{Animal studies}

All institutional and national guidelines for the care and use of laboratory animals were followed.

\section{Compliance with ethical standards}

Conflict of interest The authors declare that they have no conflict of interest.

\section{Ethical statement}

\section{- Ethics approval and consent to participate :}

All procedures performed were in accordance with the ethical standard of the institutional and national research committee and with 1964 Helsinki declaration and its later amendments or comparable ethical standards. The animal study was approved by Faculty of Pharmacy, Tanta University Ethical Committee (approval number (2042016). 
- Consent for publication :

Not applicable

- Availability of data and materials :

The datasets generated and /or analyzed during the current study are not publicly available but are available from the corresponding author on reasonable request

\section{- Competing interests :}

The authors declare that they have no conflict of interest

\section{- Funding :}

The research did not receive any specific grant from funding agencies in the public, commercial. Or not for profit sectors.

\section{- Authors 's contributions :}

Abdalla, KF: protocol development and research design, data collection and management, data analysis and manuscript writing/ editing. Osman, MA: protocol development and supervision. Nouh, AT: protocol development and supervision. El Maghraby, GM: protocol development and research design, writing and revision of manuscript, data analysis and supervision.

\section{- Acknowledgements :}

Not applicable.

\section{References}

1. Rajkumar M, Bhise SB. Carbamazepine-loaded porous microspheres for short-term sustained drug delivery. J Young Pharm. 2010;2(1): 7-14.

2. Charulatha R, Rajan RK. Design and evaluation of Carbamazepine controlled release drug delivery system. Int. J. PharmTech Res. 2012;4(1): 25-34.

3. Brodie MJ, Mintzer S, Pack AM, Gidal BE, Vecht CJ, Schmidt D. Enzyme induction with antiepileptic drugs: Cause for concern. Epilepsia. 2013;54(1):11-27.

4. Sadat SMA, Saiful Islam M, Jahan ST, Chowdhury JA, Jalil R. Effect of cellulosic and polymethacrylic polymers on drug content, particle morphology, and Carbamazepine release profiles from sustained release Ethyl Cellulose microspheres. Dhaka Univ. J. Pharm. Sci. $2010 ; 9(2)$ : 75-82.

5. Patel H, Panchal DR, Patel U, Brahmbhatt T, Suthar M. Matrix type drug delivery system: A review. JPSBR. 2011;1(3):143-51. 
6. Gupta BP, Thakur N, Jain NP, Banweer J, Jainm S. Osmotically controlled drug delivery system with associated drugs. J Pharm Pharm Sci. 2010;13(4): 571-88.

7. Sivaneswari S, Veena D, Sai Sumana P, Subhashree P, Ramya L, Rajalakshmi R, Chandana PJ, Karthikeyan E. Ion exchange resins as drug delivery carriers. J. Chem. Pharm. Res. 2015;7(4):143645.

8. Patil RS, Kemkar VU, Patil SS. Microsponge drug delivery system : A novel dosage form. Am. J. Pharm Tech Res. 2012;2(4):227-51.

9. Singhvi G, Manchanda P, Hans N, Dubey SK, Gupta G. Microsponge: An emerging drug delivery strategy. Drug Dev Res. 2018;1-9.

10. Desavathu M, Pathuri R, Chunduru M. Design, development and characterization of Valsartan microsponges by quasi emulsion technique and the impact of stirring rate on microsponge formation. J. App. Pharm Sci. 2017;7(1):193-8.

11. Sonali, Singh RP, Prajapati SK. Formulation and evaluation of prednisolone loaded microsponges for colon drug delivery: in-vitro and pharmacokinetic study. IJPSR. 2014;5(5): 1994-2005.

12. Mowafy HA, Alanazi FK, El Maghraby GM. Development and validation of an HPLC-UV method for the quantification of carbamazepine in rabbit plasma. Saudi Pharmaceutical Journal. 2012;20:29 -34 .

13. El Maghraby GM, Alomrani AH. Synergistic enhancement of Itraconazole dissolution by ternary system formation with Pluronic F68 and Hydroxypropylmethylcellulose. Sci Pharm. 2009; 77: 40117.

14. Khan KA. The concept of dissolution efficiency. J Pharm Pharmacol. 1975; 27:48-9.

15. Donga WY, Maincent P, Bodmeier R. In vitro and in vivo evaluation of carbamazepine-loaded enteric microparticles. Int J Pharm. 2007;331: 84-92.

16. Mahmoud DB, Shukr MH, El Meshad AN. Gastroretentive microsponge as a promising tool for prolonging the release of Mitiglinide Calcium in type-2 diabetes mellitus: optimization and pharmacokinetics study. AAPS Pharm. Sci.Tech. 2018;19(6):2519-31.

17. Zhang H, Zhu Y, Qiao N, Chen Y, Gao L. Preparation and characterization of carbamazepine cocrystal in polymer solution. Pharmaceutics. 2017; 9(4):1-13.

18. Baldaniya LH, Saisivam S, Gohel MC. Formulaton, optimization, characterization and in-vitro of sustained release floating microspheres of carbamazepine. Int J Pharm Bio Sci. 2012;3(2):73-88.

19. Pinto MAL, Ambrozin B, Ferreira APG, Cavalheiro ÉTG. Thermoanalytical studies of carbamazepine: hydration/dehydration, thermal decomposition, and solid phase transitions. Brazilian Journal of Pharmaceutical Sciences. 2014;50(4):877-84.

20. Lai HL, Pitt K, Craig DQ. Characterisation of the thermal properties of ethylcellulose using differential scanning and quasi-isothermal calorimetric approaches. Int. j. pharm. 2010:386:178-84.

21. Mayur K, Ramesh K, Nitin J, Prashant P, Rajendra G, Jeevan N. Ethyl cellulose based microsponge delivery system for antifungal vaginal gels of tioconazole. Journal of Drug Delivery and 
Therapeutics. 2013; 3(6):14-20.

22. Osmani RAM, Aloorkar NH, Thaware BU, Kulkarni PK, Moin A, Hani U, Bhosale RR. Microsponge based drug delivery system for augmented gastroparesis therapy: Formulation development and evaluation. Asian journal of pharmaceutical sciences. 2015; 10: 442-51.

23. Ivanova NA, Trapani A, Di Franco C, Mandracchia D, Trapani G, Franchini C, Bratoeva KZ. In vitro and ex vivo studies on diltiazem hydrochloride-loaded microsponges in rectal gels for chronic anal fissures treatment. Int.J, Pharm. 2019; 557:53-65.

24. Barakh Ali SF, Rahman Z, Dharani S, Afrooz H, Khan MA. Chemometric models for quantification of Carbamazepine anhydrous and dihydrate forms in the formulation. J. Pharm. Sci. 2019;108:1211-19.

25. Barakat NS, Radwan MA. In vtro performance of Carbamazepine loaded to various molecular weights of Poly (D, L-lactide-co-glycolide). Drug Delivery. 2006;13:9-18.

26. Nair R, Kumar ACK, Priya VK, Yadav CM, Raju PY. Formulation and evaluation of chitosan solid lipid nanoparticles of carbamazepine. Lipids in Health and Disease. 2012;11(72):1-8.

27. Trivedi MK, Branton A, Trivedi D, Nayak G, Mishra RK, Jana S. Characterization of physicochemical and thermal properties of biofield treated Ethyl cellulose and Methyl Cellulose. International Journal of Biomedical Materials Research. 2015; 3(6): 83-91.

28. Huang J, Wigent RJ, Schwartz JB. Drug-polymer interaction and its significance on the physical stability of Nifedipine amorphous dispersion in microparticles of an ammonio methacrylate copolymer and ethylcellulose binary blend. J. Pharm. Sci. 2007;97(1):251-62.

29. Zhao Y, Bao Y, Wang J, Rohani S. In situ focused beam reflectance measurement (FBRM), attenuated total reflectance fourier transform infrared (ATR-FTIR) and Raman characterization of the polymorphic transformation of Carbamazepine. Pharmaceutics. 2012; 4: 164-78.

30. Mao D, Li Q, Bai N, Dong H, Li D. Porous stable poly(lactic acid)/ethyl cellulose/hydroxyapatite composite scaffolds prepared by a combined method for bone regeneration. Carbohydrate Polym. 2018; $180: 104-11$.

31. Parida P, Mishrab SC, Sahoo S, Behera A, Nayak BP. Development and characterization of ethylcellulose based microsphere for sustained release of nifedipine. J. Pharm. Anal. 2014:1-5.

32. Bhatia M, Saini M. Formulation and evaluation of curcuma microsponges for oral and topical drug delivery. Prog. Biomater. 2018;7: 239-48.

33. Jain AS, Date AA, Pissurlenkar RRS, Coutinho EC, Nagarsenker MS. Sulfobutyl Ether7ß-Cyclodextrin (SBE7 $\beta-C D)$ Carbamazepine Complex: preparation, characterization, molecular modeling, and evaluation of in Vivo anti-epileptic activity. AAPS Pharm. Sci. Tech. 2011;12(4):1163-75.

34. Parmar GR, Gandhi KS, Sailor GU, Chauhan SP, Seth AK. Influence of Ethylcellulose on dissolution profile of Carbamazepine Cyclodextrin complex. Int. J. Pharm. Res. 2014:6 (1): 43-47.

35. Sharmin S, Elias NM, Ahmed I. Effects of ethyl cellulose and hydroxyl propyl methyl cellulose on the release profile of diltiazim hydrochloride sustained released pellets. World Journal of pharmaceutical research. 2015; 4(5):93-108. 
36. Obiedallah MM, Abdel-Mageed AM, Elfaham TH. Ocular administration of acetazolamide microsponges in situ gel formulations. Saudi Pharm J. 2018; 26(7): 909-20.

37. Mastiholimath VS, Dandagi PM, Gadad AP, Mathews R, Kulkarni AR. In vitro and in vivo evaluation of ranitidine hydrochloride ethyl cellulose floating microparticles. Journal of Microencapsulation. 2008; 25(5): 307-14.

38. Rukhadze MD, Alexishvili MM, Okujava NV, Sebiskveradze MV, Okujava VM, Tsagareli SK. Interaction of carbamazepine and phenobarbital in rabbits. Biomed. Chromatogr. 2000;14: 344-48.

39. Medhi B, Singh PK, Prakash A, Avti P. Effect of esomeprazole on the pharmacokinetics of carbamazepine. Indian J Pharmacol. 2011;43(1):73-5.

40. Comoglu T, Savaser A, Ozkan Y, Gonul N, Baykara T. Enhancement of ketoprofen bioavailability by formation of microsponge tablets. Pharmazie. 2007; 62(1):51-4.

\section{Tables}

Table 1 The composition of the tested formulations.

\begin{tabular}{|lllllll|}
\hline Formulation & $\begin{array}{l}\text { Drug polymer } \\
\text { ratio }\end{array}$ & $\begin{array}{l}\text { Drug } \\
(\mathrm{mg})\end{array}$ & $\begin{array}{l}\text { EC } \\
(\mathrm{mg})\end{array}$ & $\begin{array}{l}\text { DCM } \\
(\mathrm{ml})\end{array}$ & $\begin{array}{l}\text { PVA } \\
(\mathrm{g})\end{array}$ & $\begin{array}{l}\text { Distilled Water } \\
(\mathrm{ml})\end{array}$ \\
\hline F0 & - & - & 800 & 20 & 0.1 & 100 \\
\hline F1 & $1: 4$ & 200 & 800 & 20 & 0.1 & 100 \\
\hline F2 & $1: 4$ & 200 & 800 & 20 & 0.5 & 100 \\
\hline F3 & $1: 4$ & 200 & 800 & 20 & 1 & 100 \\
\hline F4 & $1: 5$ & 200 & 1000 & 20 & 0.1 & 100 \\
\hline F5 & $1: 5$ & 200 & 1000 & 20 & 0.5 & 100 \\
\hline F6 & $1: 5$ & 200 & 1000 & 20 & 1 & 100 \\
\hline F7 & $1: 6$ & 200 & 1200 & 20 & 0.1 & 100 \\
\hline F8 & $1: 6$ & 200 & 1200 & 20 & 0.5 & 100 \\
\hline F9 & $1: 6$ & 200 & 1200 & 20 & 1 & 100 \\
\hline
\end{tabular}

DCM is dichloromethane, EC is ethyl cellulose and PVA is polyvinyl alcohol. Stirring rate was $500 \mathrm{rpm}$ for 4 hours. $F_{0}$ is plain ethyl cellulose microsponges.

Table 2 The characteristics of the prepared microsponges 


\begin{tabular}{|lllllll|}
\hline & PY\% & Particle size $(\mathrm{m})$ & Drug content (\%) & EE\% & RE \% $2 \mathrm{hr}$ & RE \% 8hr \\
\hline C & - & - & - & - & 58.11 & 87.39 \\
& & & & & $(2.13)$ & $(2.04)$ \\
\hline F & - & 371 & - & - & - & - \\
& & $(10)$ & & & & \\
\hline F1 & 53.25 & 528 & 7.32 & 36.61 & 34.33 & 71.43 \\
& $(0.90)$ & $(17.43)$ & $(0.47)$ & $(2.37)$ & $(1.51)$ & $(0.48)$ \\
\hline F2 & 43.97 & 486 & 9.25 & 46.30 & 31.61 & 68.34 \\
& $(1.07)$ & $(31.06)$ & $(0.37)$ & $(1.87)$ & $(1.66)$ & $(0.36)$ \\
F3 & 40.48 & 388 & 12.39 & 62.09 & 30.29 & 66.39 \\
& $(2.06)$ & $(24.97)$ & $(1.64)$ & $(8.05)$ & $(1.99)$ & $(0.82)$ \\
F4 & 60.22 & 547 & 7.73 & 46.59 & 22.67 & 55.67 \\
& $(11.88)$ & $(31.30)$ & $(0.81)$ & $(4.91)$ & $(0.95)$ & $(1.73)$ \\
\hline F5 & 56.16 & 546 & 9.77 & 58.91 & 19.18 & 53.96 \\
& $(5.25)$ & $(34.94)$ & $(0.40)$ & $(2.83)$ & $(2.23)$ & $(1.32)$ \\
\hline F6 & 44.09 & 544 & 11.73 & 70.67 & 21.64 & 55.76 \\
& $(5.22)$ & $(31.49)$ & $(1.07)$ & $(6.48)$ & $(4.17)$ & $(3.87)$ \\
\hline F7 & 63.44 & 629 & 9.23 & 64.72 & 14.88 & 45.86 \\
& $(7.86)$ & $(13.96)$ & $(0.53)$ & $(3.74)$ & $(0.74)$ & $(0.83)$ \\
\hline F8 & 59.24 & 609 & 11.02 & 77.20 & 15.68 & 44.59 \\
& $13.75)$ & $(39.20)$ & $(0.38)$ & $(2.72)$ & $(0.49)$ & $(0.54)$ \\
\hline F9 & 47.58 & 598 & 12.64 & 88.59 & 18.59 & 45.26 \\
& $(8.97)$ & $(47.72)$ & $(0.22)$ & $(1.51)$ & $(0.63)$ & $(0.45)$ \\
\hline
\end{tabular}

EE is the entrapment efficiency and RE is the release efficiency. Values between brackets are SD, $n=3$.

Table 3 Rlease kinetic models of all formulation. 


\begin{tabular}{|c|c|c|c|c|}
\hline \multirow[t]{2}{*}{ Formula code } & Zero order & First order & Higuchi & Krosmeyers-Peppas \\
\hline & \multicolumn{4}{|c|}{ Stomach phase (2hr.) } \\
\hline F1 & 0.700 & 0.950 & 0.974 & 0.348 \\
\hline F2 & 0.805 & 0.947 & 0.992 & 0.467 \\
\hline F3 & 0.590 & 0.903 & 0.927 & 0.228 \\
\hline F4 & 0.787 & 0.773 & 0.931 & 0.378 \\
\hline F5 & 0.814 & 0.697 & 0.874 & 0.423 \\
\hline F6 & 0.787 & 0.767 & 0.924 & 0.358 \\
\hline F7 & 0.743 & 0.986 & 0.978 & 0.341 \\
\hline F8 & 0.727 & 0.851 & 0.771 & 0.308 \\
\hline \multirow[t]{2}{*}{ F9 } & 0.575 & 0.958 & 0.924 & 0.216 \\
\hline & \multicolumn{4}{|c|}{ Intestinal phase (6hr.) } \\
\hline F1 & 0.989 & 0.934 & 0.994 & 0.191 \\
\hline F2 & 0.987 & 0.834 & 0.9865 & 0.104 \\
\hline F3 & 0.984 & 0.875 & 0.983 & 0.161 \\
\hline F4 & 0.957 & 0.892 & 0.943 & 0.419 \\
\hline F5 & 0.976 & 0.901 & 0.962 & 0.423 \\
\hline F6 & 0.987 & 0.955 & 0.978 & 0.533 \\
\hline F7 & 0.984 & 0.988 & 0.992 & 0.712 \\
\hline F8 & 0.941 & 0.961 & 0.949 & 0.775 \\
\hline \multirow[t]{2}{*}{ F9 } & 0.937 & 0.980 & 0.950 & 0.887 \\
\hline & \multicolumn{4}{|c|}{ Combined stomach and intestinal phase $(8 \mathrm{hr})}$, \\
\hline F1 & 0.724 & 0.933 & 0.984 & 0.449 \\
\hline F2 & 0.759 & 0.876 & 0.985 & 0.565 \\
\hline F3 & 0.732 & 0.921 & 0.973 & 0.451 \\
\hline F4 & 0.857 & 0.942 & 0.966 & 0.623 \\
\hline F5 & 0.900 & 0.947 & 0.956 & 0.699 \\
\hline F6 & 0.884 & 0.973 & 0.968 & 0.625 \\
\hline F7 & 0.953 & 0.986 & 0.946 & 0.744 \\
\hline
\end{tabular}




\begin{tabular}{|lllll|} 
F8 & 0.938 & 0.976 & 0.944 & 0.676 \\
F9 & 0.919 & 0.979 & 0.947 & 0.550 \\
\hline
\end{tabular}

Table 4 Pharmacokinetics parameters of carbamazepine after oral administration to albino rabbits

\begin{tabular}{|lll|}
\hline Parameters & Control & Test \\
\hline AUC $(0 \rightarrow 24)$ & $12.45 \pm 0.325$ & $32.32 \pm 10.47$ \\
$(\mathrm{mg} \cdot \mathrm{hr} / \mathrm{ml})$ & & \\
$\mathrm{C}_{\max 1}(\mathrm{mg} / \mathrm{ml})$ & $0.68 \pm 0.055$ & $2.41 \pm 0.61$ \\
\hline $\mathrm{C}_{\max 2}(\mathrm{mg} / \mathrm{ml})$ & $0.55 \pm 0.059$ & -- \\
\hline Kel $\left(\mathrm{h}^{-1}\right)$ & $0.065 \pm 0.02$ & $0.088 \pm 0.08$ \\
\hline $\mathrm{T}_{1 / 2}$ & $11.34 \pm 3.5$ & $7.85 \pm 0.67$ \\
\hline $\mathrm{T}_{\max }(\mathrm{h})$ & 3 and 8 hours & 8 hours \\
\hline
\end{tabular}

Data are presented as an average $\pm S D, n=3$.

\section{Figures}




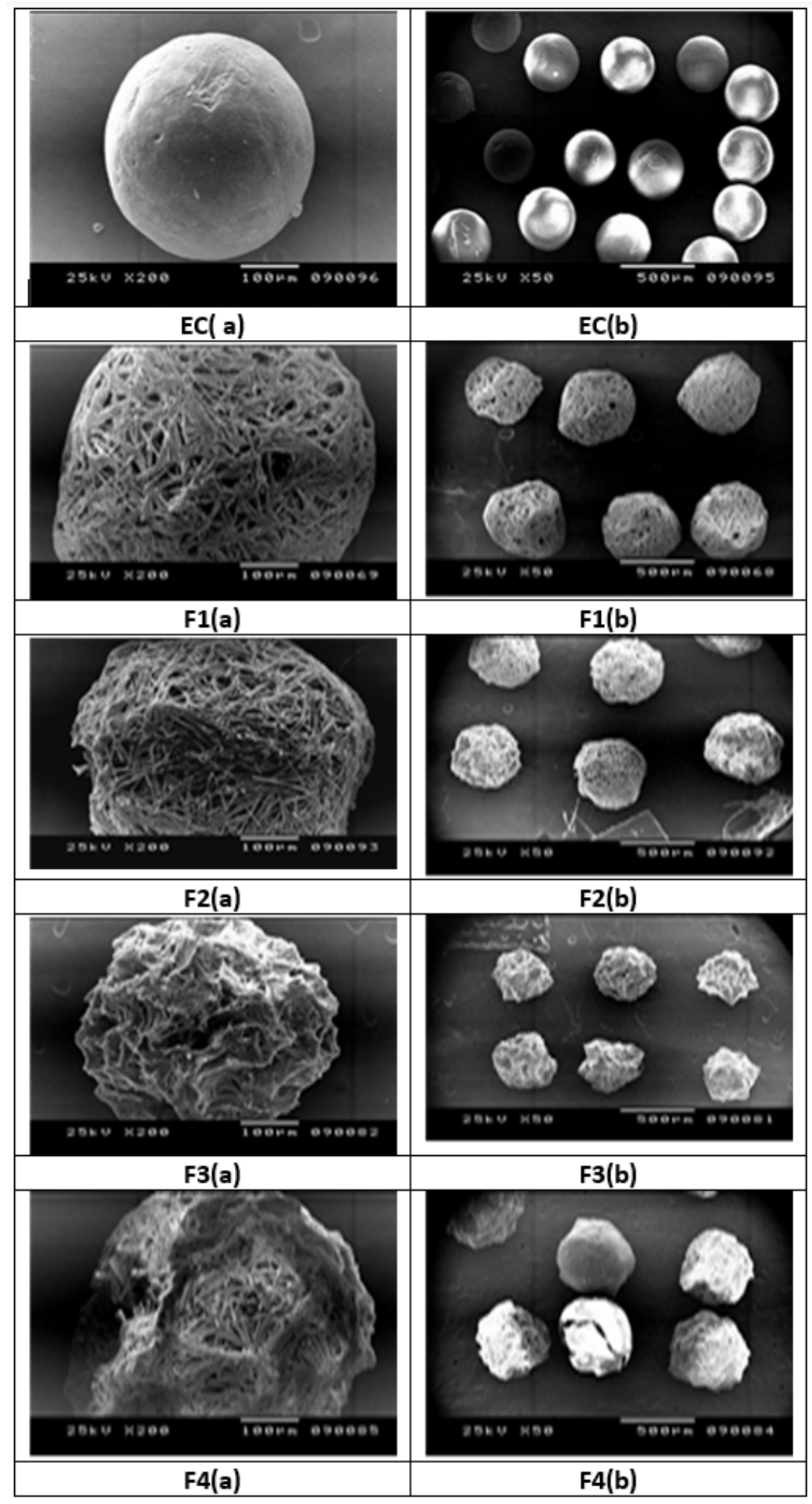

Figure 1

Scanning electron micrographs of plain ethyl cellulose microsponges and microsponges prepared according to formulations F1-F4, presented at magnification power of 200X (a) and 50X (b). Formulation details are in Table 1. 


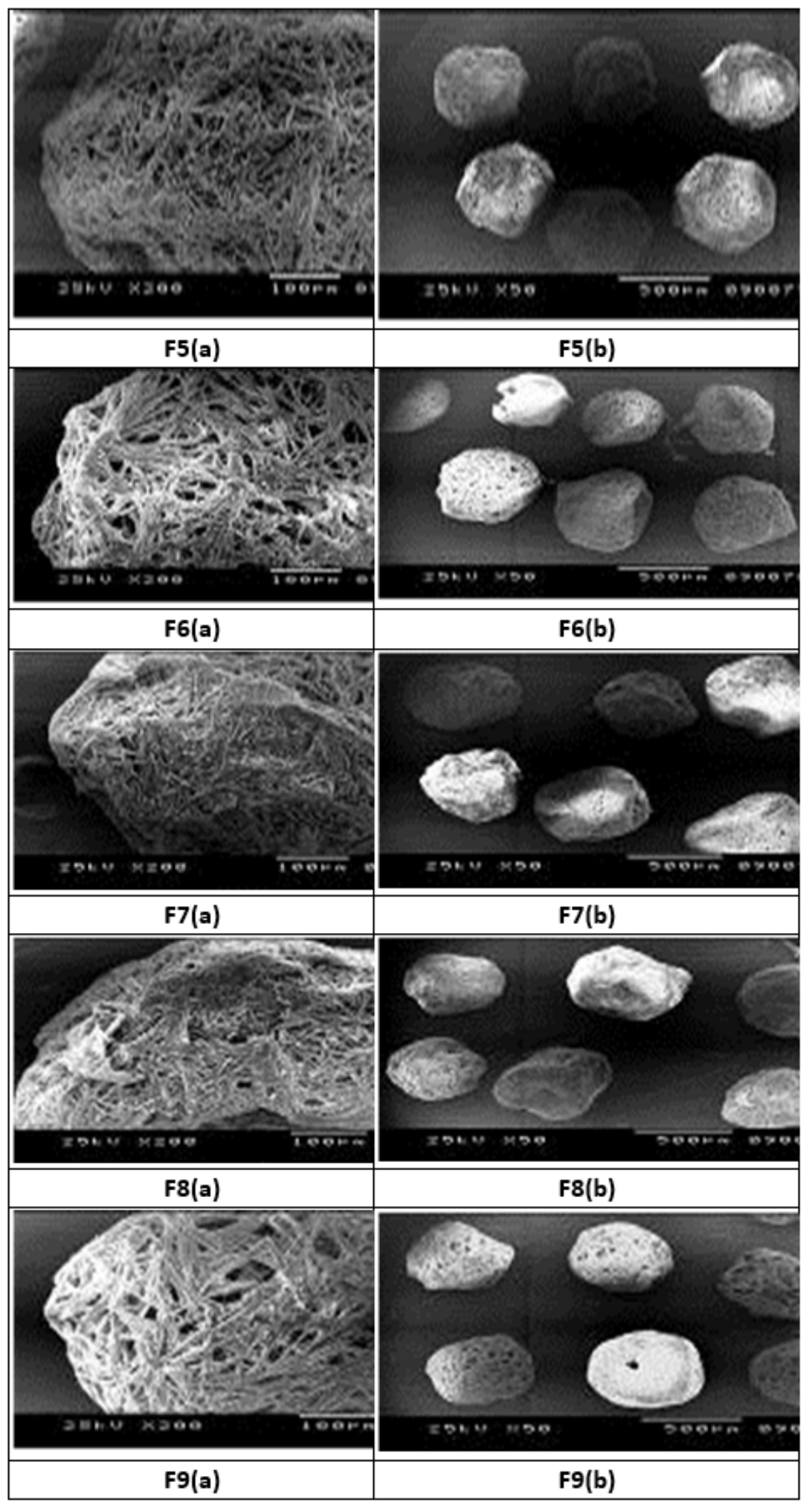

Figure 2

Scanning electron micrographs of microsponges prepared according to formulations F5-F9, presented at magnification power of 200X (a) and 50X (b). Formulation details are in Table 1. 

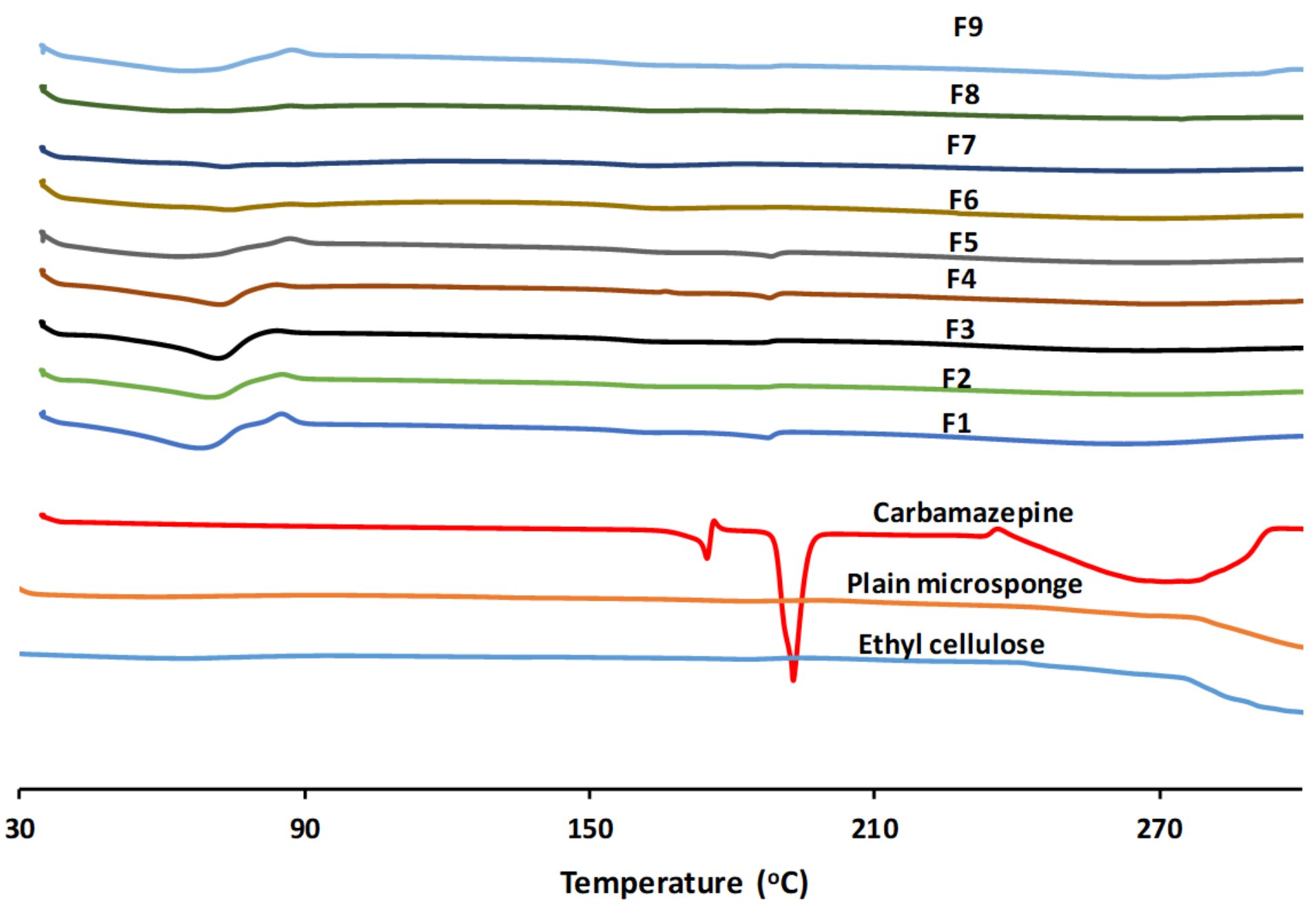

\section{Figure 3}

Thermograms of carbamazepine in pure state and after encapsulation in different microsponge formulations. Formulations details are in Table 1. 
F9

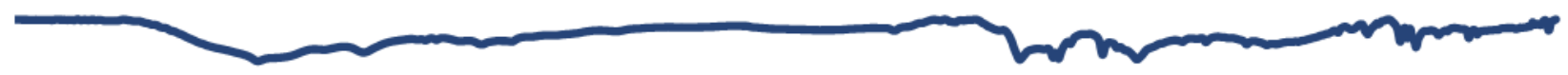

F8

F7
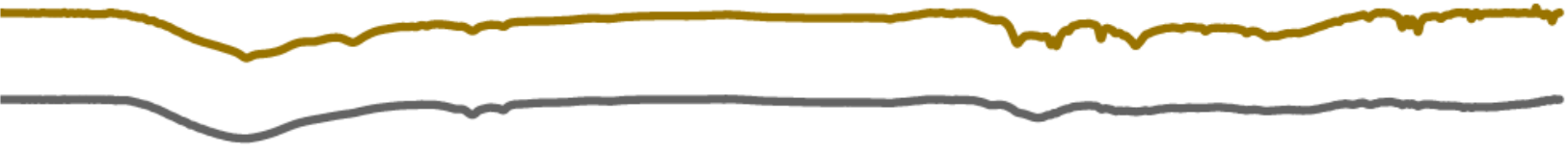

F6

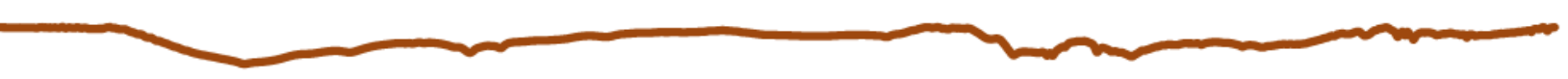

F5
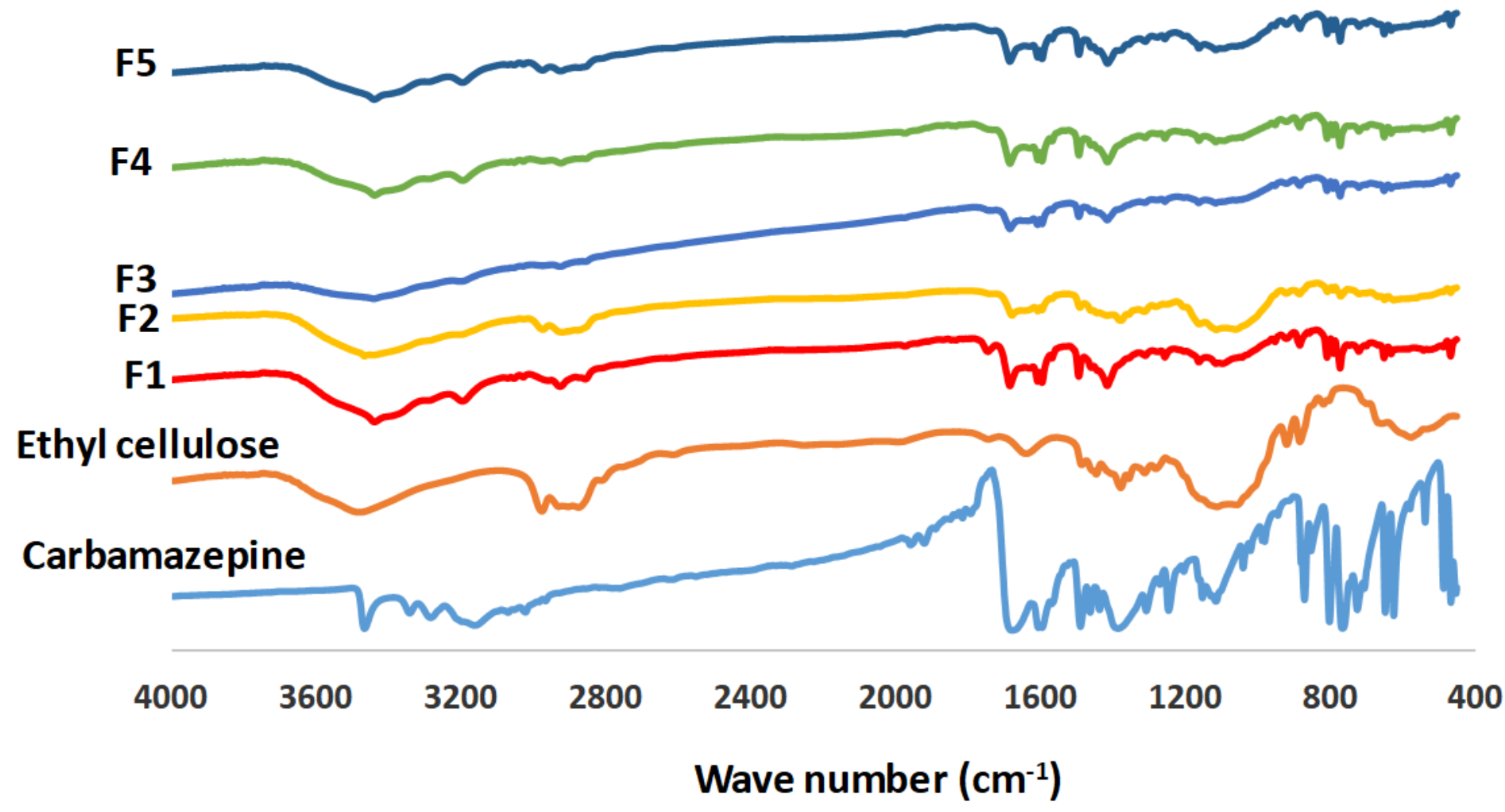

Figure 4

FTIR spectra of carbamazepine in pure state and after encapsulation in microsponges. Formulation details are in Table 1. 


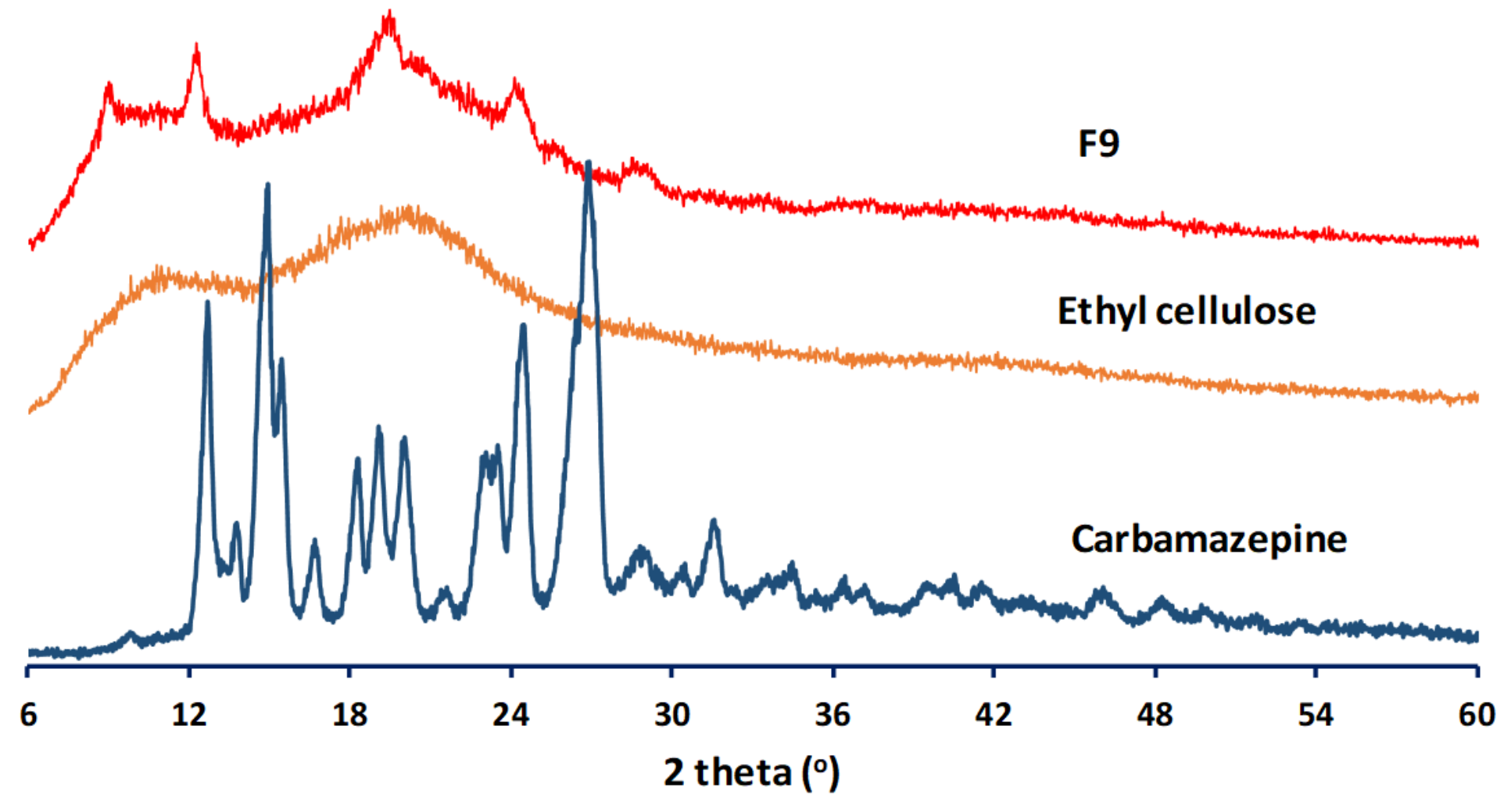

Figure 5

X-ray diffraction pattern of unprocessed carbamazepine, ethyl cellulose and the optimum microsponge formulation (F9). The composition of F9 is in Table 1. 


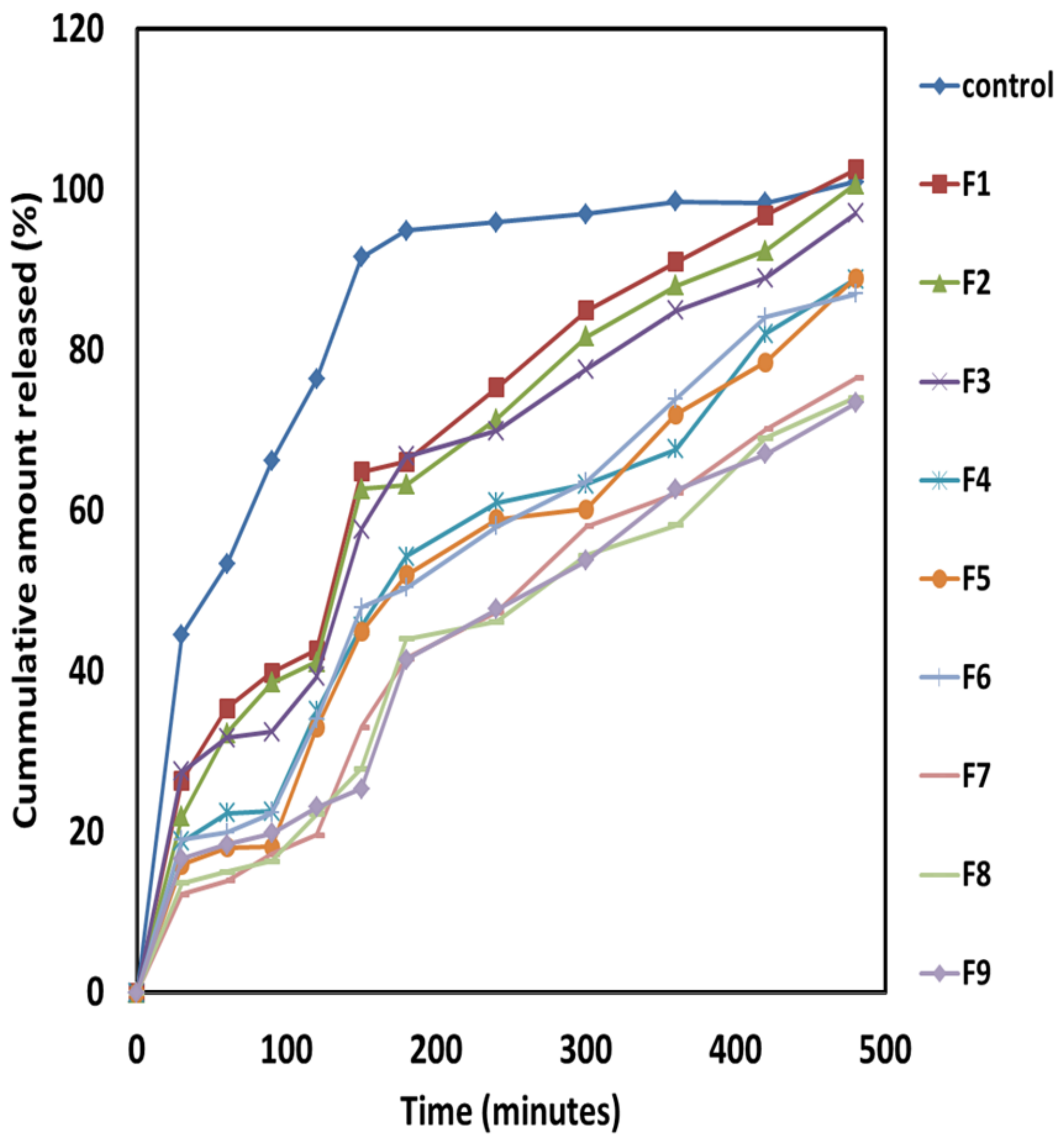

Figure 6

In vitro release of carbamazepine from microsponges having different composition. Formulation details are in Table 1. 


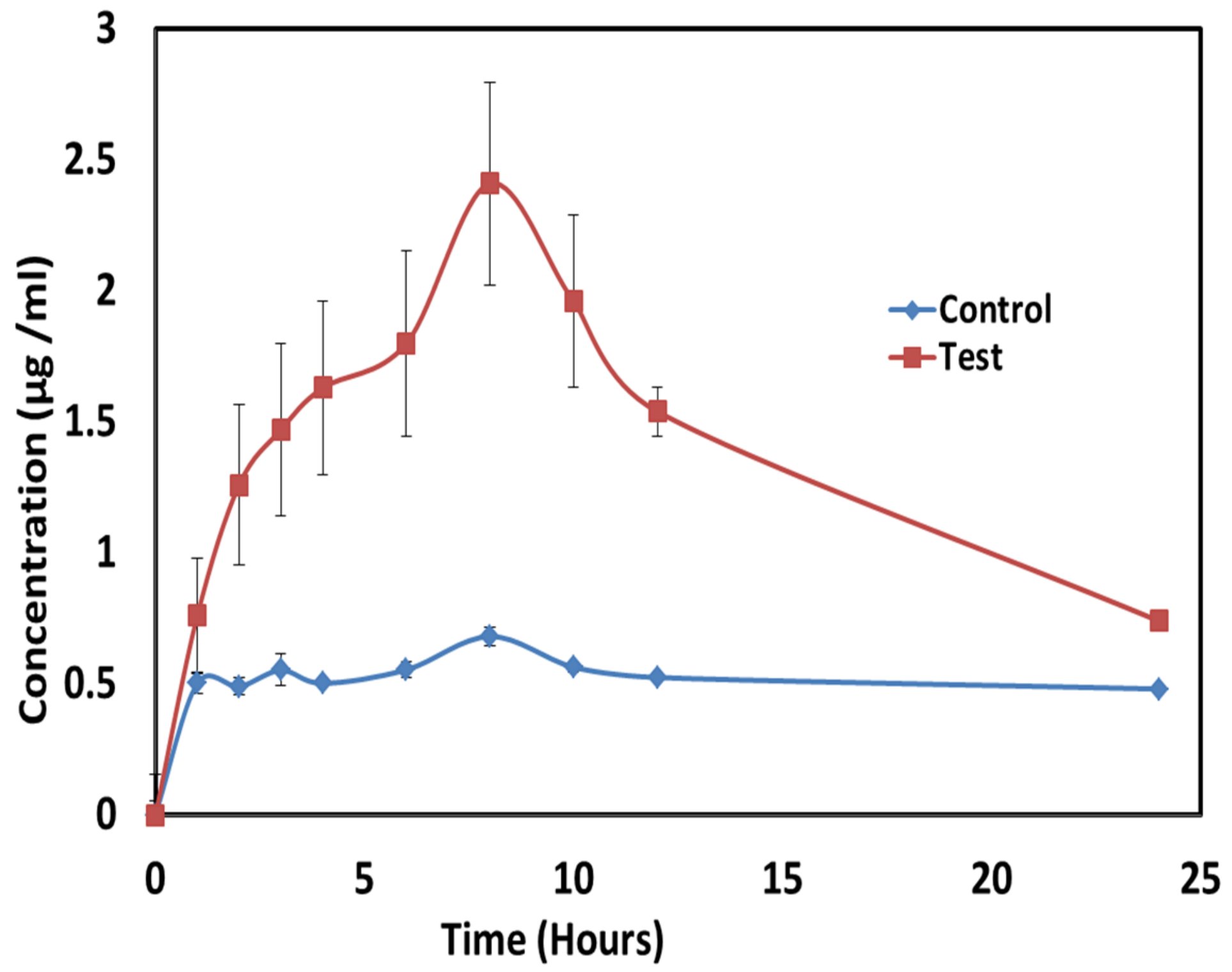

Figure 7

Plasma concentration versus time curves obtained after administration of carbamazepine to albino rabbits in the form of unprocessed drug suspension or as microsponges .

\section{Supplementary Files}

This is a list of supplementary files associated with this preprint. Click to download.

- GraphicalAbstract.png 